\section{INVESTIGACIÓN MULTIDISCIPLINAR Y TRASLACIONAL EN ENFERMEDADES RARAS}

\author{
Santiago Rodríguez de Córdoba \\ Centro de Investigaciones Biológicas, Consejo Superior de \\ Investigaciones Científicas / Centro de Investigación Biomédica \\ en Red de Enfermedades Raras (CIBERER) \\ ORCID iD: https://orcid.org/0000-0001-6401-1874 \\ SRdeCordoba@cib.csic.es \\ Carmelo Bernabéu \\ Centro de Investigaciones Biológicas, Consejo Superior de \\ Investigaciones Científicas / Centro de Investigación Biomédica \\ en Red de Enfermedades Raras (CIBERER) \\ ORCID iD: https://orcid.org/0000-0002-1563-6162 \\ bernabeu.c@cib.csic.es
}

Cómo citar este artículo/Citation: Rodríguez de Córdoba, S. y Bernabéu. C. (2018). Investigación multidisciplinar y traslacional en enfermedades raras. Arbor, 194 (789): a468. https://doi.org/10.3989/arbor.2018.789n3010

Recibido: 30 abril 2015. Aceptado: 13 mayo 2016.

RESUMEN: Dentro de las enfermedades raras, las enfermedades hereditarias constituyen un grupo mayoritario que incluye las ocasionadas por mutaciones en un solo gen (monogénicas) o aquellas ocasionadas por más de un gen (poligénicas). Descubrir que un determinado gen se asocia con el desarrollo de una patología se ha convertido en un paradigma de la investigación biomédica actual que tiene enormes repercusiones en la práctica clínica. Así, el diagnóstico molecular, basado en la búsqueda de mutaciones en los genes asociados a una patología, no solo se ha convertido en un refuerzo imprescindible del diagnóstico clínico, sino que frecuentemente aporta criterios a ese diagnóstico que permiten un manejo personalizado de los pacientes. Sin embargo, nos hemos familiarizado tanto con términos como genes, genoma humano o secuenciación de $A D N$ que frecuentemente olvidamos que la identificación de un gen como responsable de una enfermedad es a menudo solo el punto de partida de un largo proceso cuyos objetivos fundamentales son establecer los mecanismos moleculares que determinan la patología y el desarrollo de estrategias que la eviten o la remedien. En este artículo revisaremos los avances recientes en dos patologías raras, una poligénica, el síndrome hemolítico urémico atípico, y otra monogénica, la telangiectasia hemorrágica hereditaria, para ilustrar el modelo de investigación multidisciplinar que caracteriza a la investigación biomédica actual y cómo el conocimiento generado en esta área se ha trasladado a la práctica clínica.

PALABRAS CLAVE: Enfermedades raras; enfermedades hereditarias; patología renal; patología vascular; complemento; endotelio; anemia; hemorragia.

\section{MULTIDISCIPLINARY AND TRANSLATIONAL RESEARCH ON RARE DISEASES}

Copyright: (c) 2018 CSIC. Este es un artículo de acceso abierto distribuido bajo los términos de la licencia de uso y distribución Creative Commons Reconocimiento 4.0 Internacional (CC BY 4.0).

ABSTRACT: Hereditary diseases constitute a major group within the rare diseases that includes those caused by mutations in a single gene (monogenic) or in more than one gene (multigenic). The discovery that a certain gene is associated with the development of a disease has become a paradigm of current biomedical research with huge implications in clinical practice. Hence, molecular diagnosis based on the search for mutations in genes associated with a disease, has not only become essential to support the clinical diagnosis, but often provides diagnostic criteria that allow customized patient management. Although we have become familiar with terms like genes, Human Genome or DNA Sequencing, we often forget that the identification of a gene responsible for a disease is only the starting point of a long process whose main objectives are to establish the molecular mechanisms underlying the pathology and the development of strategies to prevent or cure the disease. Here, we will review recent advances in two rare diseases, one multigenic, the atypical hemolytic uremic syndrome, and the other one monogenic, the hereditary hemorrhagic telangiectasia, to illustrate the model of multidisciplinary research that characterizes current biomedical research and how the knowledge generated in this area has been transferred to clinical practice.

KEYWORDS: Rare diseases; hereditary diseases; renal pathology; vascular pathology; complement; endothelium; anemia; bleeding. 


\section{EL SÍNDROME HEMOLÍTICO URÉMICO ATÍPICO COMO MODELO DE ENFERMEDAD RARA MULTIGÉNICA}

El síndrome hemolítico urémico (SHU) es un trastorno de la microvasculatura clínicamente definido por anemia hemolítica microangiopática (producida por fragmentación de los eritrocitos) y plaquetopenia, que afecta preferentemente a los riñones y se manifiesta con hematuria, oligoanuría y fracaso renal. El daño al endotelio de la microvasculatura glomerular parece ser el primer suceso en la patogénesis del SHU. Este daño endotelial dispara la formación de microtrombos que ocluyen las arteriolas y los capilares renales (microangiopatía trombótica), causando la rotura de los eritrocitos que atraviesan esta microvasculatura parcialmente ocluida. Tradicionalmente se distinguen dos formas de SHU. La forma más frecuente ( $90 \%$ de los casos) se denomina SHU clásico o típico y está asociado a diarrea provocada por infección de escherichia coli, productor de la toxina shiga. En la mayoría de los pacientes el SHU típico es consecuencia de intoxicaciones por consumo de alimentos contaminados por esta bacteria. Normalmente son casos agudos que evolucionan satisfactoriamente al cabo de dos o tres semanas, aunque el $10 \%$ evolucionan hacia enfermedad renal crónica y un $25 \%$ desarrollan secuelas renales permanentes. El trasplante renal en estos casos es una alternativa terapéutica con buenos resultados (Repetto, Rodríguez de Córdoba, Arrizurieta, Rivas e Ibarra, 2008).

Por exclusión, a los casos de SHU que no están asociados con diarrea provocada por escherichia coli (aproximadamente un 10\%) se les denomina SHU atípico (SHUa), enfermedad ultra-rara, no asociada a diarrea y de mucho peor pronóstico que el SHU típico, con una mortalidad elevada. La mayoría de los pacientes presentan recurrencias y más de un $50 \%$ desarrollan una insuficiencia renal terminal. El trasplante renal en estos casos no es aconsejable porque la enfermedad recidiva frecuentemente en el injerto. Esta forma atípica de SHU tiene una incidencia de aproximadamente dos casos por millón de habitantes y año, y una prevalencia de $1 / 10^{5}$ niños en la Unión Europea (Noris y Remuzzi, 2009). La existencia de familias con múltiples casos de SHUa hacía suponer un componente genético en esta variante de SHU que en algunos casos se había identificado como una deficiencia en plasma de la proteína factor $\mathrm{H}$ del complemento. Sin embargo, fue un trabajo pionero basado en un estudio GWLA (Genome-wide linkage analysis) con tres extensas familias de SHUa el que definitivamente estableció la asociación genética del complemento con el SHUa (Warwicker et al., 1998). Este estudio demostró que la herencia del SHUa en estas tres familias estaba ligada al agrupamiento de genes reguladores de la activación del complemento (RCA, Regulators of Complement Activation), que codifica proteínas reguladoras del complemento en el cromosoma 1 humano e identificó que en una de estas familias una mutación en el gen de factor $\mathrm{H}$ se asociaba con el desarrollo de la patología. Estos resultados inmediatamente provocaron una serie de estudios adicionales que han delineado la predisposición genética a SHUa, identificando mutaciones asociadas a la patología en muchos otros genes del complemento y proporcionado conocimientos fundamentales sobre sus mecanismos patogénicos. Estos hallazgos han cambiado la percepción de que el SHUa era una patología relacionada con hipocomplementemia (carencia de complemento) y han conducido a la comprensión de que la enfermedad se inicia por el daño endotelial causado por el complemento como consecuencia de su regulación deficiente sobre las superficies celulares (Rodríguez de Córdoba, Esparza Gordillo, Goicoechea de Jorge, López-Trascasa y Sánchez-Corral, 2004).

\subsection{El Sistema del complemento}

El complemento es un componente fundamental de la inmunidad innata, donde juega un papel crucial en la defensa contra infecciones, en la eliminación de restos apoptóticos, en el procesamiento de inmunocomplejos y en la modulación de la inmunidad adaptativa (Ricklin, Hajishengallis, Yang y Lambris, 2010). El complemento es un complejo sistema molecular organizado por un conjunto de proteínas en plasma y en las superficies celulares que una vez activado funciona como un sistema de amplificación en cascada. Es capaz de disparar señales de alarma ante la presencia de agentes extraños al organismo, de discriminar componentes propios y extraños y, mediante un sistema de etiquetado molecular, de identificar estos últimos para su eliminación por opsonofagocitosis o su destrucción mediante lisis celular directa. El complemento es un arma de doble filo que requiere una regulación estricta para focalizar su acción sobre la superficie responsable de su activación (patógenos, células apoptóticas o complejos inmunes) y para evitar que se consuma completamente tras dicha activación. Esto se consigue por la acción concertada de un conjunto de proteínas reguladoras en el plasma y en las superficies celulares que actúan en distintos niveles, pero sobre todo controlando la actividad de las enzimas responsables del circuito de amplificación y limitando el depósito de la etiqueta molecular (el 
fragmento activo $\mathrm{C} 3 \mathrm{~b})$ sobre los componentes propios. La pérdida de regulación del complemento lleva inevitablemente a su consumo, con la generación de componentes activos, y al daño accidental de los propios tejidos. Ambas situaciones tienen consecuencias patológicas. De hecho, durante estos últimos años numerosos estudios han asociado mutaciones y polimorfismos que alteran la función de las proteínas reguladoras del complemento con un importante número de enfermedades en las que la inflamación crónica, el daño tisular o la susceptibilidad a infecciones juegan un papel relevante. El SHUa se ha convertido en el paradigma de este conjunto de enfermedades que incluye otras enfermedades raras, como la Glomerulopatía C3 o la hemoglobulinuria paroxística nocturna (PNH), y enfermedades comunes como la Degeneración Macular Asociada a la Edad (DMAE), la Nefropatía IgA (NIgA), el Lupus Eritematoso Sistémico (LES), las infecciones por neumococo o la enfermedad de Alzheimer (EA) (Holers, 2008).

\subsection{Mecanismos patogénicos. SHUa, una lesión causada por el complemento}

El SHUa se asocia con mutaciones o polimorfismos en los genes que codifican las proteínas reguladoras del complemento como factor $\mathrm{H}(\mathrm{CFH})$, proteína cofactor de membrana (MCP), y el factor I (CFI), y con mutaciones en los genes que codifican componentes del complemento como el factor B (CFB) y C3 (C3) (Rodríguez de Córdoba, Subías-Hidalgo, Pinto y Tortajada, 2014). Las mutaciones en CFH son prototípicas del SHUa y constituyen la alteración genética más frecuente entre estos pacientes. Representan aproximadamente el $15 \%$ de los pacientes con SHUa en todas las series. Las mutaciones en CFH asociadas con SHUa se agrupan en el extremo C-terminal de la proteína, una región que es crítica para que el factor $\mathrm{H}$ se una a las superficies celulares y controle la activación local del complemento. Los portadores de estas mutaciones en CFH expresan moléculas de factor $\mathrm{H}$ que poseen actividad reguladora normal en plasma, pero una capacidad limitada para unirse y proteger las células de la lisis mediada por el complemento. La caracterización funcional de las mutaciones en factor $\mathrm{H}$ asociadas a SHUa ha establecido que para desarrollar SHUa se requieren ambos, la combinación de un sistema de complemento activo en plasma y una protección defectuosa de las superficies celulares (Rodríguez de Córdoba, Tortajada, Harris y Morgan, 2012). Posteriormente, el análisis funcional de mutaciones en otros genes del complemento ha confirmado las conclusiones generadas en los estudios con mutaciones en factor $\mathrm{H}$ (Atkinson, Liszewski, Richards, Kavanagh y Moulton, 2005).

Entre los pacientes con SHUa hay un grupo (de 5 al $10 \%$ del total, dependiendo de las cohortes) que presenta autoanticuerpos anti-factor $\mathrm{H}$ con consecuencias similares a las de las mutaciones en factor $\mathrm{H}$. Los autoanticuerpos anti factor $\mathrm{H}$ asociados con SHUa van dirigidos contra la región C-terminal de la molécula de factor $\mathrm{H}$ y bloquean específicamente la capacidad de factor $\mathrm{H}$ de regular la activación del complemento sobre las superficies celulares. Los autoanticuerpos anti-factor $\mathrm{H}$ tal vez sean la explicación a posteriori de algunos casos de SHUa para los que no se ha encontrado un defecto genético en los genes del complemento (Dragon-Durey et al., 2005).

La penetrancia de la enfermedad en los portadores de mutaciones en genes del complemento es aproximadamente del $50 \%$, siendo habitual que en familias en las que se han identificado mutaciones solo algunos portadores desarrollen la enfermedad. Además, la presentación clínica de la enfermedad entre familiares puede variar significativamente. También existe una gran heterogeneidad clínica entre pacientes no emparentados portadores de la misma mutación. Todo ello sugiere que deben existir factores adicionales (genéticos y ambientales) que modulan el desarrollo y la evolución de la enfermedad. Hoy en día se acepta que entre los factores desencadenantes del SHUa están las infecciones (frecuentemente del tracto respiratorio), los fármacos inmunosupresores, los tratamientos anticancerosos, los anticonceptivos orales y el embarazo, entre otros. En relación con los factores genéticos adicionales, la presencia de mutaciones en más de un gen de complemento aporta ese factor adicional en el 7 al $10 \%$ de pacientes con SHUa. Sin embargo, el factor genético que contribuye más frecuentemente al desarrollo de la enfermedad en los portadores de mutaciones es la presencia de determinados polimorfismos en los genes que codifican el factor $\mathrm{H}$ (CFH) y la proteína cofactor de membrana (MCP) (Rodríguez de Córdoba et al., 2014). Numerosos trabajos resaltan la importancia de realizar un análisis genético completo de los pacientes para determinar lo más precisamente posible los factores de riesgo genético de padecer SHUa que llevan el paciente y sus familiares, pues se ha observado que los individuos afectos de SHUa en familias que presentan más de un factor de riesgo son aquellos que acumulan el mayor número de esos factores de riesgo.

En resumen, los estudios de laboratorio desarrollados durante estos últimos años han establecido que 
el SHUa es una patología compleja, poligénica y multifactorial en la que participan tanto factores genéticos como ambientales. Los niveles disminuidos o la pérdida de actividad de factor $\mathrm{H}$, de factor $\mathrm{I}$, de MCP, la generación de autoanticuerpos anti-factor $\mathrm{H}$ o de mutaciones "activadoras" en factor B o C3 predisponen a contraer SHUa porque impiden una regulación adecuada del complemento sobre las superficies celulares. Así, las situaciones que disparen la activación del complemento en la microvasculatura no se podrán controlar de modo apropiado en el nivel del endotelio vascular, ocasionando su destrucción y la formación de microtrombos que ocluirán las arteriolas y los capilares renales. Este concepto de lesión causada por el sistema del complemento justifica, como veremos más adelante, la aplicación de estrategias inhibidoras del complemento en el tratamiento del SHUa. Las proteínas del complemento factor $\mathrm{H}$, factor I, factor B y C3 son proteínas plasmáticas sintetizadas fundamentalmente por el hígado, mientras que MCP se localiza en las superficies celulares. Estas características son importantes a la hora de aplicar tratamientos con plasma y en el trasplante renal (véase más adelante).

\subsection{Relevancia de las mutaciones en la evolución y el tratamiento de los pacientes con SHUa}

Numerosos datos apoyan la tesis de que la presentación clínica de la enfermedad está relacionada con el hecho de tener o no mutaciones en genes del complemento, y sobre todo con el gen particular que está mutado (Ariceta et al., 2009). Los pacientes con mutaciones en factor $\mathrm{H}$ tienen una presentación más agresiva y quedan con secuelas más importantes, mientras que los pacientes con mutaciones en MCP son los que tienden a evolucionar mejor, aunque son los que presentan más recurrencias.

La infusión de plasma o los recambios plasmáticos son las estrategias terapéuticas empleadas habitualmente tras la aparición de un primer episodio de SHUa y han permitido disminuir la mortalidad de un 50 a un $25 \%$ de los casos. Diversos grupos que trabajan en SHU han publicado las pautas que se aconseja seguir en el tratamiento de SHUa (Ariceta et al., 2009, Campistol et al., 2013). La infusión de plasma permite reemplazar los reguladores del complemento con mutaciones pérdida de función por proteínas funcionales, mientras que los recambios plasmáticos son oportunos para la eliminación de las proteínas con mutaciones ganancia de función o de los autoanticuerpos anti-factor $\mathrm{H}$. En el caso de mutaciones en $\mathrm{MCP}$, los tratamientos con plasma no deberían tener efecto alguno. De hecho, es una observación generalizada que la evolución de estos pacientes no mejora con tratamientos plasmáticos.

Antes o después, los enfermos con SHUa necesitan un trasplante renal. En este sentido es importante considerar también que la experiencia acumulada en estos últimos años muestra que el resultado del trasplante está condicionado por el gen del complemento que está mutado. Por ejemplo, en pacientes con mutaciones en factor $\mathrm{H}$ o en factor I, proteínas plasmáticas sintetizadas principalmente en el hígado, la recurrencia de la enfermedad en el riñón trasplantado es de aproximadamente el $80 \%$. Sin embargo, en los pacientes con mutaciones en MCP, el éxito del trasplante es muy elevado, debido a que el MCP expresado en el injerto corrige el defecto genético del paciente. En estos pacientes la recidiva de la enfermedad en el órgano trasplantado es solo del $20 \%$. En los trasplantes realizados en pacientes con autoanticuerpos anti-factor- $\mathrm{H}$, realizar una plasmaféresis previa al trasplante que disminuya el título de autoanticuerpos parece ser una buena opción para evitar la recurrencia.

\subsection{Inhibidores del complemento}

La aplicación de terapias basadas en la utilización de inhibidores del complemento se ha demostrado eficaz para prevenir o reducir el daño causado por la activación del complemento. En la actualidad existen varios inhibidores del complemento con potencial aplicación en SHUa, pero solo uno de ellos, el eculizumab (Soliris; Alexion Pharmaceuticals), está aprobado para el tratamiento del SHUa. El eculizumab es un anticuerpo monoclonal humanizado que se une a la proteína del complemento C5 con gran afinidad, evitando su activación y que el complemento proceda por la vía terminal organizando el complejo de ataque a las membranas y dañando las superficies celulares. En el SHUa la desregulación del complemento provoca la activación descontrolada de C5, que ocasiona un importante daño tisular mediante la formación del complejo de ataque a la membrana. El bloqueo de la vía terminal del complemento con eculizumab reduce de forma rápida y permanente este daño tisular.

La eficacia y seguridad del eculizumab frente al SHUa se demostró inicialmente en dos estudios prospectivos multicéntricos de fase 2 (C08-002 y C08-003; Legendre et al., 2013). Tras 26 semanas de tratamiento, ambos estudios mostraron una normalización de los parámetros hematológicos y una ausencia de fenómenos de microangiopatía trombótica en la mayoría de los pacientes, así como una mejoría continuada de la función 
renal y una reducción de la necesidad de diálisis en un número significativo de ellos. Además, cuanto más temprana fue la intervención con eculizumab mayor fue la mejoría de la función renal. Los resultados de los estudios de extensión a uno y tres años demostraron una mejoría progresiva de la respuesta hematológica y de la función renal. Hay que señalar que todos estos resultados positivos con eculizumab se observaron indistintamente en pacientes con o sin alteraciones genéticas y con anticuerpos anti-Factor $\mathrm{H}$.

En general la tolerancia al eculizumab fue correcta y satisfactoria, y únicamente se han indicado unos pocos eventos adversos graves relacionados con el tratamiento, que probablemente tengan que ver con la propia patología de base. Debido a su mecanismo de acción, el eculizumab podría incrementar el riesgo de infección por gérmenes encapsulados, por lo que todos los pacientes son vacunados contra neisseria (vacuna tetravalente) catorce días antes de iniciar el tratamiento y normalmente reciben profilaxis antibiótica.

Actualmente se encuentran en marcha otros dos estudios de fase 3, multicéntricos, prospectivos y abiertos, sobre la terapia con eculizumab en pacientes con SHUa (C10-004 y C10-003; Fakhouri et al., 2013, Greenbaum et al., 2013) que, a diferencia de los estudios anteriores, incluyen mayoritariamente pacientes recién diagnosticados de SHUa. Los resultados de estos estudios confirman la mejoría hematológica y de la función renal observada en los estudios iniciales, así como los beneficios del uso temprano de eculizumab. El perfil de seguridad fue también similar, aunque en uno de estos estudios se han observado dos casos de meningitis meningocócica (5\%). Ambas infecciones se controlaron adecuadamente y uno de los pacientes incluso continuó con el eculizumab. En otro estudio retrospectivo de diecinueve pacientes pediátricos tratados con eculizumab durante 28 semanas de media (C09-001), en el 89\% de los pacientes se normalizaron los parámetros hematológicos y en el $68 \%$ se mantuvieron libres de eventos de microangiopatía trombótica. La función renal mejoro en el $47 \%$ de los pacientes y el $50 \%$ suspendió la hemodiálisis.

\subsection{Búsqueda de nuevos genes asociados con SHUa}

A pesar de los avances de estos últimos años, en un 30 o $40 \%$ de pacientes con SHUa no se identifica un gen responsable ni se detecta la presencia de anticuerpos anti-factor $\mathrm{H}$. Estos pacientes no son diferentes de los que llevan mutaciones en genes del complemento, por lo que es posible que lleven mutaciones en otros genes del complemento.
Recientemente se han identificado mutaciones en la proteína anticoagulante trombomodulina que predisponen a desarrollar SHUa porque alteran la regulación del complemento en superficies celulares. Si bien estos resultados concuerdan con la desregulación del complemento característica del SHUa, se desconoce si los mutantes de trombomodulina asociados con el SHUa tienen también alterada la actividad anticoagulante y, por lo tanto, si las alteraciones de esta actividad pudieran ser también relevantes en el SHUa. En este sentido, un estudio reciente ha evaluado mediante secuenciación de ADN masiva en 36 pacientes con SHUa la presencia de mutaciones en los genes del sistema del complemento y de la coagulación, encontrando mutaciones en genes de ambos sistemas. Aunque estos datos sugieren una contribución de los genes de la coagulación -en particular de plasminógeno (PLG)- en la predisposición al SHUa, son necesarios estudios adicionales que confirmen estas observaciones (Rodríguez de Córdoba et al., 2014).

La búsqueda de nuevos genes asociados con el SHUa se ha abordado también utilizando la secuenciación de exomas (Lemaire et al., 2013). Así, se han identificado mutaciones en homocigosis en el gen DGKE, que codifica la proteína quinasa épsilon del diacilglicerol (DGK- $\varepsilon$ ) en pacientes que tuvieron un debut muy temprano del SHUa, normalmente durante el primer año de vida, seguido de múltiples recurrencias que frecuentemente les llevaron a fracaso renal terminal en la segunda década de la vida. Aunque las consecuencias del déficit de DGK- $\varepsilon$ no se han establecido todavía, una posibilidad es que en ausencia de DGK- $\varepsilon$ aumente la señalización intracelular y la activación de la proteína quinasa C en células endoteliales, en plaquetas y podocitos, y con ello se genere un estado protrombótico al elevarse la síntesis de proteínas como el factor von Willebrand, el inhibidor 1 del activador de plasminógeno, el factor activador de plaquetas o el factor tisular. Además, la pérdida de DGK- $\varepsilon$ podría alterar la homeostasis del podocito y el diafragma de filtración, lo que explicaría la elevada proteinuria que se observa en pacientes con mutaciones en DGKE. Aunque el papel del complemento en el desarrollo de la enfermedad renal en los portadores de mutaciones en DGKE se había descartado inicialmente, recientemente se han identificado pacientes con mutaciones en DGKE que además llevan mutaciones en otros genes previamente asociados con el SHUa, como THBD y C3 (Rodríguez de Córdoba et al., 2014).

\subsection{Retos actuales de la investigación en SHUa}

Con el desarrollo de técnicas de cribado masivo de genes del complemento, el número de variantes 
en genes del complemento asociadas con el SHUa y otras patologías relacionadas con desregulación del complemento alcanza ya varios centenares. Las consecuencias funcionales de muchas de estas variantes son desconocidas, lo que genera incertidumbres y dificulta la toma de decisiones sobre el manejo y el tratamiento de los pacientes. Es fundamental disponer de un mapa que correlacione aspectos estructurales y funcionales para cada uno de los eventos moleculares implicados en la activación y en la regulación del sistema del complemento, pues la comprensión de esta relación estructura-función permitirá en un futuro una interpretación inmediata de las consecuencias funcionales de las variantes genéticas en los genes del complemento encontradas en los pacientes. La caracterización funcional y estructural de variantes genéticas en proteínas del complemento es, además, una oportunidad única para profundizar en los mecanismos moleculares implicados en la activación y en la regulación del sistema del complemento. Claramente en estos momentos este es un argumento circular, pues será a través de un conocimiento profundo de los aspectos funcionales y estructurales de las proteínas del complemento como generaremos el mapa que nos permitirá interpretar en el futuro las consecuencias funcionales de las mutaciones que encontremos.

La ausencia de marcadores específicos robustos que pongan de manifiesto desregulación o activación del complemento en el SHUa u otras enfermedades relacionadas con el complemento es una dificultad que impide anticipar el debut o los episodios de estas enfermedades. Los niveles de C3 en plasma tienen un significado pronóstico limitado y la identificación de fragmentos activados de proteínas del complemento plantea todavía dificultades técnicas. De hecho, la mayoría de los pacientes con SHUa no presentan alteraciones del complemento en plasma que sugieran una desregulación del complemento. Del mismo modo, el valor de estos marcadores para evaluar la eficacia de los tratamientos anticomplemento o la remisión de la enfermedad es muy limitado. Creemos que es necesario desarrollar marcadores biológicos que se fundamenten en los mecanismos patogénicos específicos de cada enfermedad. En este sentido, dado que SHUa es una enfermedad caracterizada por una desregulación específica sobre las superficies celulares, parece oportuno desarroIlar ensayos específicos que evalúen esta situación y valoren la desregulación y la activación del complemento simulando las condiciones fisiológicas en las que se desarrolla la enfermedad.

\subsection{Conclusiones}

Hemos resumido los avances que han permitido descifrar los mecanismos patogénicos del SHUa a través de la caracterización funcional de variantes genéticas del complemento. Estos avances y la generación de modelos animales apropiados han facilitado el desarrollo de terapias para el tratamiento del SHUa basadas en la utilización de inhibidores del complemento, que están cambiando la historia natural de la enfermedad. Del mismo modo, es cada vez más evidente que un conocimiento individualizado de los factores genéticos de riesgo de desarrollar SHUa facilita el manejo personalizado de los pacientes. El conocimiento de los factores genéticos de predisposición de los pacientes y el desarrollo de biomarcadores que permitan un seguimiento de la patología serán imprescindibles en el diseño de ensayos clínicos apropiados que determinen la eficacia de futuras terapias. Estos son retos importantes que de nuevo requieren un enfoque multidisciplinar y la implementación de una evaluación de rutina entre la investigación clínica y la básica. En esta interacción, el conocimiento básico en complemento contribuirá a comprender las mutaciones asociadas a la enfermedad y a desentrañar los mecanismos patogénicos, y a su vez la investigación clínica, a través de la identificación de nuevas variantes genéticas patogénicas y de la explotación de registros de pacientes, ayudará a los estudios básicos, facilitando en su conjunto la explotación del conocimiento generado en los entornos clínico, básico e industrial.

\section{LA TELANGIECTASIA HEMORRÁGICA HEREDITARIA COMO MODELO DE ENFERMEDAD RARA MONOGÉNICA}

La telangiectasia hemorrágica hereditaria (HHT) o Síndrome de Rendu-Osler-Weber es una enfermedad hereditaria autosómica dominante. Existen al menos cuatro genes diferentes mutados en la $\mathrm{HHT}$, a saber, ENG, ACVRL1, GDF2 y MADH4, que codifican para las proteínas endoglina ( $E N G$ ), el receptor de activina ALK1 con actividad serina-treonina quinasa (ACVRL1), la proteína morfogenética del hueso BMP9 (GDF2) y Smad4 (MADH4), respectivamente. Estas proteínas están implicadas en la vía de señalización de la superfamilia del factor de crecimiento transformante (TGF)- $\beta$ en las células endoteliales vasculares. Las mutaciones en ENG (HHT1) y ACVRL1 (HHT2) representan más del $90 \%$ de todas las mutaciones de la HHT. En este apartado revisaremos las manifestaciones clínicas, la genética, las bases moleculares y celulares subyacentes, los modelos animales y los enfoques terapéuticos de la HHT que han sido estudiados en los últimos años. 


\subsection{Manifestaciones clínicas de la HHT}

La HHT es una enfermedad vascular asociada con sangrados nasales (epistaxias), telangiectasias, hemorragias gastrointestinales y malformaciones arteriovenosas (MAV) en pulmón, hígado y cerebro. Las telangiectasias se visualizan como pequeñas manchas rojas en la piel, en la cavidad bucal, en la punta de los dedos y en la nariz. Estas pequeñas lesiones vasculares aparecen como dilataciones focales en las vénulas post-capilares que se agrandan posteriormente, conectándose con las arteriolas dilatadas y dando lugar a la pérdida del lecho capilar. Por otra parte, las MAV se generan a partir de pequeñas lesiones vasculares mediante un proceso progresivo de remodelado vascular. La prevalencia de la HHT es de alrededor de 1-2 en 10.000, según varias revisiones (Abdalla y Letarte, 2006; Shovlin et al., 2000). La enfermedad está incluida en la base de datos de Herencia Mendeliana en el Hombre (Mendelian Inheritance in Man, MIM), cuyo editor es el doctor Victor A. McKusick (http://www. ncbi.nlm.nih.gov/omim). El diagnóstico se basa en criterios clínicos, conocidos como los criterios de Curaçao (Shovlin et al., 2000). Así, una persona es considerada como un paciente de HHT si cumple al menos tres de los cuatro criterios siguientes: i) epistaxias espontáneas y recurrentes; ii) múltiples telangiectasias en lugares característicos (labios, cavidad oral, dedos, nariz); iii) lesiones viscerales en órganos internos (telangiectasias gastrointestinales, MAV pulmonares, hepáticas, cerebrales o espinales; o iv) un familiar de primer grado con HHT. La enfermedad HHT no es aparente en el nacimiento, sino que evoluciona con la edad en un patrón fenotípico reconocible. La penetrancia de la enfermedad aumenta con la edad y en torno a los 45 años es aproximadamente del $90 \%$. Hombres y mujeres se ven afectados por igual y cada uno puede transmitir la enfermedad a aproximadamente la mitad de sus hijos, en consonancia con el desarrollo de la enfermedad en los individuos heterocigotos para una mutación en un gen HHT. Varios estudios de investigación en niños con dos progenitores afectados sugieren fuertemente la letalidad in utero de los individuos homocigotos. Dado que los pacientes pueden tener MAV en el pulmón y en el cerebro mucho antes de que aparezcan los síntomas más evidentes, como son la aparición de epistaxias y telangiectasias, el establecimiento de un diagnóstico molecular temprano es necesario. Estas malformaciones pueden dar lugar a complicaciones, como el ictus cerebral, el infarto cerebral, los abscesos cerebrales, la hemoptisis masiva y la parálisis. Existen guías clínicas internacionales para el diagnóstico y tratamiento de la HHT (Shovlin et al., 2000; Faughnan et al., 2011).

\subsection{Genética de la HHT}

La HHT es una enfermedad autonómica dominante. Existen cuatro genes cuyas variantes patógenicas pueden causar la HHT. El primer gen identificado fue endoglina ( $E N G)$, que se localiza en el cromosoma 9 y afecta a un porcentaje del 39 al 59\% de la población total afectada por HHT. A continuación, fue descrito el gen ACVRL1 (también conocido como ALK1) que está en el cromosoma 12 y que es responsable de entre el 25 y el $57 \%$ de los casos de HHT. Hasta la fecha, se han descrito más de 600 mutaciones patogénicas diferentes en ENG y ACVRL1. Las mutaciones en ENG y ACVRL1 dan lugar a los subtipos de la enfermedad, HHT1 y HHT2 respectivamente, y es de resaltar que los pacientes de HHT1 y de HHT2 constituyen más del 90\% de la población total de pacientes de HHT. En alrededor del $2 \%$ de la población total $\mathrm{HHT}$, el origen de la enfermedad es una mutación en el gen MADH4 que da lugar al síndrome combinado de poliposis juvenil (JP) y HHT (JPHT), aunque se ha encontrado un solapamiento de espectros en las mutaciones de $\mathrm{MADH} 4$ en JP y JPHT. Se ha descrito que ciertas mutaciones en el gen GDF2 dan lugar al fenotipo HHT5, aunque la población afectada es minoritaria, ya que representa menos del $<1 \%$ de la población total HHT (Wooderchak-Donahue et al., 2013). Además de los genes HHT conocidos, dos loci adicionales se han descrito en el cromosoma 5 y en el cromosoma 7, pero sus genes responsables no han sido todavía identificados. Existe una base de datos con las mutaciones descritas hasta ahora en los genes HHT (http://arup.utah.edu/database/HHT/). La detección de las mutaciones patogénicas concretas en los genes HHT es considerada como un diagnóstico molecular muy útil, dado que puede servir para identificar a posibles familiares afectados, aunque en ellos no se haya manifestado una evidente sintomatología. Este diagnóstico molecular es especialmente relevante en los niños, debido a que la aparición de los síntomas tiene lugar generalmente en la edad adulta, y útil también para el diagnóstico genético preimplantacional cuando se pretende seleccionar un embrión libre de la mutación patogénica del gen HHT (Abdalla y Letarte, 2006).

\subsection{Correlaciones genotipo-fenotipo}

Todas las características clásicas de la HHT se pueden ver en los distintos subtipos, en especial en la HHT1 y en la HHT2, pero la prevalencia de anomalías vasculares específicas varía según el genotipo. Las MAV pulmonares son más comunes en la HHT1 que en la HHT2, aunque en el número relativamente pequeño de pacientes JP-HT descrito hasta ahora la prevalencia 
de las MAV pulmonares puede ser todavía mayor. Los pacientes HHT1 también son más comúnmente afectados por las MAV cerebrales y por un cortocircuito (shunting) intrapulmonar microscópico. En una cohorte de pacientes de $\mathrm{HHT}$, la ecocardiografía de contraste positivo, que refleja el cortocircuito intrapulmonar, se encontró en el $85 \%$ de los pacientes de HHT1 y en el $35 \%$ de los pacientes de HHT2, en comparación con el $7 \%$ de una población de control. En cuanto a las MAV hepáticas y a la enfermedad grave asociada, los pacientes de HHT2 son los que tienen una mayor prevalencia. El estudio de una serie de pacientes sugiere que los de HHT2 pueden tener más MAV pancreáticas y desarrollar más temprano las telangiectasias de piel que los de HHT1. Algunas características de la HHT descritas y no incluidas en los criterios de Curaçao (Shovlin et al., 2000), demuestran fuertes correlaciones genotipo-fenotipo. Así, por ejemplo, la poliposis juvenil (JP) se produce en pacientes con mutaciones MADH4 y parece ser indistinguible de la JP causada por mutaciones en el gen BMPRIA. En el hombre (pero no en ratón) la hipertensión arterial pulmonar se produce predominantemente en los pacientes de HHT2, y puede tener un pronóstico peor que cuando se debe a mutaciones en el gen BMPR2. Los pacientes de HHT2 también están en mayor riesgo de hipertensión pulmonar post-capilar asociada con MAV hepáticas. Hasta ahora, no hay evidencias que sugieran que las mutaciones específicas dentro de un gen de la HHT particular confieran diferentes fenotipos relacionados con la HHT (Shovlin et al., 2000).

\subsection{Estudios traslacionales sobre la HHT}

Durante las últimas dos décadas, se han realizado grandes avances sobre el conocimiento de los genes ENG y ACVRL1 y de las proteínas codificadas por ellos, tanto mediante experimentos in vivo como in vitro. Estos estudios han permitido concluir que la haploinsuficiencia es la causa de la patogenicidad en las mutaciones de ENG (HHT1) y ACVRL1 (HHT2) en los dos subtipos mayoritarios de la HHT. Este mecanismo de haploinsuficiencia postula que existe una deficiente expresión o función de las proteínas que codifican los genes de la HHT en el alelo mutado y que esta deficiencia es la causa de la sintomatología de la enfermedad (Abdalla y Letarte, 2006).

\subsubsection{Modelos animales de la HHT}

Nuestra comprensión de por qué las mutaciones de los genes de la enfermedad conducen a la patología vascular ha avanzado considerablemente gracias a la generación de modelos animales de la HHT. Los rato- nes homocigóticos nulos para ENG y ACVRL1 mueren entre los días 10.5-11.5 después de la gestación, debido a graves defectos cardiacos y vasculares, lo que demuestra el importante papel que juegan estos dos genes durante el desarrollo embrionario. Esta falta de viabilidad explicaría la ausencia de pacientes homocigóticos para los genes de la HHT. Por el contrario, los ratones heterocigotos para ENG y ACVRL1 son viables y de alguna forma mimetizan la haploinsuficiencia de estos genes en los pacientes de HHT. De hecho, estos ratones heterocigotos muestran la sintomatología característica de la $\mathrm{HHT}$, incluyendo hemorragias nasales, telangiectasias, vasos dilatados y MAV en pulmón, hígado y cerebro. Algunos datos sugieren que las mutaciones de la HHT pueden ser perjudiciales durante algunas formas de angiogénesis, con efectos específicos sobre la estabilidad de los brotes vasculares recién formados. El proceso fisiológico de la angiogénesis conlleva la formación de nuevos vasos sanguíneos derivados de otros vasos preexistentes y está presente en el desarrollo embrionario, en el crecimiento del organismo, así como en la cicatrización de heridas. Durante la angiogénesis existen breves períodos de activación de células endoteliales, donde la proliferación y la migración están coordinadas con un reclutamiento controlado de las células murales circundantes (pericitos o células de músculo liso), la remodelación proteolítica de la membrana basal y la matriz extracelular y la expresión de factores de supervivencia de células endoteliales. Así, ciertos factores proangiogénicos tales como el factor de crecimiento endotelial vascular (VEGF) regulan diferencialmente las subpoblaciones de células endoteliales en el brote angiogénico, controlando independientemente la migración endotelial en células especializadas de punta (tip cells) y la proliferación en el tallo. Curiosamente, se ha encontrado que endoglina es prescindible para la vasculogénesis (formación de vasos de novo), pero es necesaria para la angiogénesis vascular inducida por VEGF. Las células murales son después reclutadas para estabilizar los vasos sanguíneos nacientes, donde existe una fuerte implicación del factor de crecimiento transformantebeta (sistema TGF- $\beta$ ) en este proceso de estabilización del vaso. Aunque estos animales heterocigotos mimetizan los síntomas de la enfermedad en humanos, existe una gran variabilidad en su fenotipo HHT que depende en gran medida del fondo genético de cada ratón. De forma similar, en humanos la sintomatología de la enfermedad varía incluso entre los distintos individuos afectados dentro de una misma familia, lo que sugiere que, además de la mutación concreta, existen otros factores genéticos o ambientales que pueden 
modular los síntomas de la HHT. En este sentido, es de resaltar que las lesiones vasculares en la HHT son muy localizadas, y que incluso dentro del lecho vascular afectado la gran mayoría de los vasos parece desarrollarse y funcionar normalmente. Este hecho ha llevado a algunos autores a postular que se requiere la perturbación de alguna función de las proteínas codificadas por los genes de la HHT (endoglina, ALK1, Smad4, BMP9), lo que en un contexto HHT de haploinsuficiencia de dichos genes daría lugar a la malformación vascular. Se ha sugerido que ciertos estímulos como la cicatrización de heridas, la angiogénesis, la inflamación, o la infección podrían ser algunos de los detonantes adicionales que darían lugar a la lesión vascular. Los modelos de ratones heterocigotos para ENG y ACVRL1 desarrollan con expresividad variable características específicas de la HHT, incluyendo sangrados nasales, telangiectasias, vasos dilatados y MAV. Por tanto, estos ratones representan el modelo animal más similar a la HHT humana. También se han generado ratones donde se ha suprimido la expresión de los genes de la HHT específicamente en células endoteliales, así como ratones que Ilevan alelos LoxP nocaut (knockout) condicionales para ENG y ACVRL1, dando lugar a modelos en los que las malformaciones vasculares aparecen de una forma más constante y predecible que en los ratones heterocigotos. La disponibilidad de todos estos modelos se presenta como una herramienta muy útil para testar nuevos medicamentos y para investigar las bases patogénicas de la HHT (Bourdeau, Dumont y Letarte, 1999; Jerkic et al., 2006; López-Novoa y Bernabéu, 2010; Mahmoud, Upton y Arthur, 2011; Srinivasan et al., 2003).

\subsubsection{Bases moleculares y celulares}

Puesto que el mecanismo patogénico de la HHT es la haploinsuficiencia, se han llevado a cabo diversos estudios para conocer en profundidad la estructura, la función y los mecanismos reguladores de la expresión de las proteínas de la HHT con objeto de encontrar vías terapéuticas para contrarrestar dicha haploinsuficiencia.

La endoglina es una glicoproteína de membrana que se expresa como un homodímero de 180 kDa unido por puentes disulfuro. Contiene un gran dominio extracelular de 561 aminoácidos, altamente glicosilados, principalmente en residuos de asparagina. Estructuralmente, la endoglina pertenece a la familia de proteínas de zona pelúcida (ZP) que comparten un dominio ZP de $\sim 260$ residuos de aminoácidos en su región extracelular. La estructura tridimensional del dominio extracelular de endoglina a $25 \AA ̊$ de resolución ha sido dilucidada utilizando microscopía electrónica.
La endoglina está dispuesta como una cúpula hecha de monómeros orientados de forma antiparalela que encierran una cavidad en un extremo. Cada subunidad comprende tres regiones bien definidas, dos de ellas correspondientes al dominio ZP. Este dominio ZP contiene un péptido RGD (Arginina-Glicina-Aspártico) que es un sitio consenso de reconocimiento celular presente en numerosas proteínas adhesivas de la matriz extracelular. La tercera región no muestra ninguna homología significativa con otras familias de proteínas / dominios y por lo tanto ha sido denominada como el dominio huérfano. La región transmembrana, abarca 25 residuos hidrofóbicos y se encuentra entre el ectodominio y la región citosólica. Se conocen dos isoformas diferentes de endoglina generadas mediante procesamiento alternativo del mRNA, la forma larga, (L)-endoglina, que es la predominante, y la forma corta, (S)-endoglina, que es minoritaria; ambas se expresan en tejidos humanos y de ratón. En humanos, las proteínas S-endoglina y L-endoglina varían entre sí en sus colas citoplasmáticas que contienen 14 y 47 aminoácidos, respectivamente. Ambas isoformas de endoglina están constitutivamente fosforiladas y pueden ser dianas de serina/treonina quinasas, incluyendo los receptores de TGF- $\beta$ tipo I (ALK1, ALK2 y ALK5) y tipo II. El dominio citoplásmico de L-endoglina contiene un motivo consenso PDZ (Serina-Serina-Metionina-Alanina) en el extremo carboxilo que media la interacción con varias proteínas que contienen el dominio de unión a PDZ.

ALK1 es una proteína transmembrana de aproximadamente $55 \mathrm{kDa}$ con un ectodominio glicosilado de 97 aminoácidos que lleva una pequeña secuencia rica en cisteínas, la cual probablemente confiere la conformación estructural apropiada para capturar el ligando. La región citoplásmica de 362 aminoácidos de ALK1 contiene: (i) un dominio GS, una secuencia conservada de 30 aminoácidos rica en glicina/serina e implicada en la regulación de la activación de los receptores; y (ii) un dominio de serina/treonina quinasa. La fosforilación de los residuos de serina/treonina de ALK1 en el dominio GS por el receptor de tipo II (TRRII) conduce a un cambio conformacional en ALK1 que permite la fosforilación de las moléculas de señalización Smad1, Smad5 o Smad8. La estructura del dominio citosólico de ALK1 contiene el bucle L45, una pequeña región que interactúa con Smads, confiriendo la especificidad de señalización entre los diferentes receptores de TGF- $\beta$ tipo I. Además, la región citosólica de ALK1 contiene un motivo de consenso para la interacción con el dominio de andamiaje de la caveolina-1, una importante proteína componente de caveolas. La mayo- 
ría de las mutaciones de ALK1 en pacientes de HHT2 implican el dominio citoplásmico, en contraposición a los de HHT1, donde las mutaciones de endoglina se localizan en el dominio extracelular.

La proteína Smad4, mutada en JP-HT, es un factor de transcripción de $\sim 60 \mathrm{kDa}$ que se transloca entre el núcleo y el citoplasma en respuesta a las señales del TGF- $\beta$. Pertenece a la familia de proteínas Smad y contiene dominios $\mathrm{MH} 1$ y $\mathrm{MH} 2$. La proteína BMP9, mutada en HHT5, es un factor soluble presente en la sangre, cuya forma activa tiene $\sim 24 \mathrm{kDa}$ y es miembro de la familia de proteínas morfogenéticas del hueso (BMP) y de la superfamilia del TGF- $\beta$ (López-Novoa y Bernabéu, 2010; Llorca, Trujillo, Blanco y Bernabeu, 2007; Mahmoud et al., 2011; Wooderchak-Donahue et al., 2013).

\subsubsection{Regulación de la expresión de los genes en la HHT}

Una forma de contrarrestar el mecanismo de haploinsuficiencia podría ser aumentar la expresión del alelo normal del gen afectado en la HHT. Esta atractiva hipótesis ha conducido a un detallado estudio de los estímulos y mecanismos que regulan la expresión de los genes en la HHT. Tanto la endoglina como ALK1 son proteínas de membrana que se expresan en células endoteliales, las cuales constituyen la diana celular principal en la HHT. La expresión de endoglina se encuentra aumentada en aquellos sitios donde hay una proliferación activa de células endoteliales asociada con neoangiogénesis, como en tejidos inflamados o infectados, en procesos de cicatrización de heridas, piel psoriásica, artritis sinovial, lesión vascular y vasos tumorales. De forma similar, una mayor expresión endotelial de ALK1 también se ha descrito en tejidos altamente vascularizados, incluyendo el pulmón, la placenta y el corazón, así como en las lesiones vasculares. Hay una variedad de estímulos responsable del aumento de la expresión de estos genes en la HHT en los vasos activados, incluyendo la hipoxia, el daño arterial y las citoquinas relacionadas. La caracterización de la región promotora de los genes ENG y ACVRL1 ha demostrado que no tienen caja TATA o CAAT, sino múltiples regiones ricas en Guanina-Citosina (CG) que reclutan el factor de transcripción Sp1 para regular su transcripción basal. Por otra parte, el estado de metilación de las islas CpG también modula la actividad de la región promotora de ambos genes. Se han descrito diversos factores de transcripción que regulan la expresión de estos genes en respuesta a diversos estímulos como la hipoxia (HIF-1 $\alpha$ ), TGF- $\beta$ (Smad) o daño vascular (KLF6). La expresión de endoglina también está regulada positivamente por los oxisteroles (pro- ductos de la oxidación del colesterol), activando el receptor nuclear LXR, el cual se une a un elemento de respuesta en el promotor de ENG. Por el contrario, el factor de necrosis tumoral- $\alpha$ (TNF- $\alpha$ ), probablemente a través del factor de transcripción NFKB, disminuye los niveles de endoglina en células endoteliales.

Muchos de los estímulos descritos como reguladores de la expresión de los genes en la HHT (angiogénesis, daño vascular, isquemia, inflamación, citoquinas, etc.) también se han postulado como posibles agentes desencadenantes de la lesión vascular de forma sinérgica con la haploinsuficiencia de los genes HHT. De hecho, la necesidad de un estímulo desencadenante para la generación de las MAV se ha demostrado usando un ratón inducible nocaut para la endoglina, donde se ha combinado un estímulo angiogénico con la supresión de endoglina. Esta podría ser la razón por la que en pacientes de HHT las lesiones vasculares solo aparecen en sitios concretos dentro de ciertos órganos, en lugar de estar presentes en todo el cuerpo y en todos los órganos o tejidos (Botella et al., 2002; López-Novoa y Bernabéu, 2010; Mahmoud et al., 2011; Shovlin, 2010).

\subsubsection{Función de las proteínas codificadas por los genes de HHT. La vía del TGF-B}

Los cuatro genes mutados identificados en la HHT (ACVRL1, ENG, MADH4 y GDF2) codifican para proteínas implicadas en la vía de señalización de TGF- $\beta$. Así: i) ALK1 es un receptor serina/treonina quinasa tipo I; ii) la endoglina es un co-receptor auxiliar sin actividad catalítica; iii) BMP9 es un miembro de la superfamilia del TGF- $\beta$ y además es un ligando soluble de ALK1 y endoglina; y iv) Smad4 es un factor de transcripción que media la señalización aguas abajo de los receptores tipo I de TGF- $\beta$. La contribución de cada uno de estos componentes en la vía de señalización ha sido elucidada. Así, en la membrana celular, la endoglina forma un complejo de proteínas con los receptores de TGF- $\beta$ tipos I y II al que se une el ligando BMP9. Esta unión desencadena una señalización intracelular dependiente del complejo de proteínas Smad que contiene Smad4. Una vez en el núcleo, el complejo de los factores de transcripción Smad regula la expresión de múltiples genes que están implicados en procesos de la biología vascular, como la angiogenesis, el remodelado vascular o la proliferación de células endoteliales. Así, por ejemplo, se ha demostrado que la endoglina modula el tono vascular al regular los niveles y la actividad de la sintetasa endotelial de óxido nítrico (eNOS) y la ciclooxigenasa-2 (COX-2), siendo estos dos enzimas claves en el control de las respuestas a la va- 
sodilatación. Curiosamente, se ha demostrado que la expresión de la isoforma S-endoglina está aumentada durante el proceso de senescencia de las células endoteliales y durante el envejecimiento de modelos animales. Puesto que en la vía de señalización de TGF- $\beta$, S-endoglina ejerce un papel antagonista al de la isoforma mayoritaria L-endoglina, estos datos sugieren que S-endoglina podría contribuir al aumento de los síntomas de HHT con la edad.

Debido a la expresión predominante de endoglina en células endoteliales, es tentador especular que la pérdida de la función de la endoglina del alelo mutante en este tipo de células es la causa de las lesiones vasculares en la HHT. Una función descrita para la endoglina es su papel protector contra la apoptosis en células endoteliales sometidas a hipoxia y tratamiento con TGF- $\beta 1$. En este contexto, la haploinsuficiencia de endoglina en la HHT puede conducir a una apoptosis masiva en las células endoteliales capilares donde se requiere la función de la endoglina para su supervivencia. Como consecuencia de la apoptosis de estas células, la red capilar desaparecería gradualmente y solo un vaso preferencial sería el que eventualmente se convertiría en el cortocircuito arterio-venoso.

Se ha descrito que la endoglina también modula funciones celulares de una forma independiente de TGF- $\beta$. Por ejemplo, la endoglina regula el citoesqueleto de actina a través de la interacción de su dominio citoplásmico con miembros de la familia de proteínas LIM, como zixina y ZRP-1. Así, las células endoteliales de pacientes de HHT muestran una morfología anormal con una deficiente organización de su citoesqueleto debida a la desorganización de las fibras de actina. La organización de la red capilar durante la angiogénesis depende de la estructura de las células endoteliales, de modo que en la vasculatura de los pacientes de $\mathrm{HHT}$, un citoesqueleto desorganizado facilitaría la rotura del endotelio con los cambios en las fuerzas de cizalladura y la presión arterial. Esto podría conducir a hemorragias de los vasos y a la eventual desaparición de la red capilar, como ocurre en la HHT.

Se ha publicado que en la célula endotelial la secuencia RGD del dominio extracelular de endoglina sirve de sitio de reconocimiento para las integrinas, que son receptores de adhesión presentes en los leucocitos. Este proceso es estimulado por señales inflamatorias y facilita el tráfico leucocitario a través del endotelio. La inflamación se ha descrito como un agente desencadenante de las lesiones vasculares en la HHT y se sabe que la infiltración leucocitaria es un proceso asociado necesario para la reparación y re- modelado vascular. Por tanto, estos datos apoyan la hipótesis de que la función de la endoglina en la adhesión celular es crítica para el desarrollo de las lesiones vasculares en la HHT (Lastres et al., 1996; LópezNovoa y Bernabéu, 2010; Mahmoud et al., 2011; Rossi et al., 2013).

\subsection{Aproximaciones terapéuticas en HHT}

Lamentablemente, hasta ahora no hay ninguna cura para la HHT y los tratamientos existentes son meramente paliativos. Por otra parte, aunque se conocen bien los genes responsables, la terapia génica no es una opción viable todavía. A continuación, se comentan algunos de los hallazgos clínicos, criterios diagnósticos y tratamientos paliativos más representativos.

\subsubsection{Malformaciones arteriovenosas pulmonares}

Las MAV pulmonares suelen ser múltiples y se localizan fundamentalmente en los lóbulos inferiores. Las principales complicaciones clínicas son: i) existencia de un cortocircuito entre sangre oxigenada y no oxigenada a nivel pulmonar, lo que conlleva a una deficiente oxigenación y la aparición de disnea, cianosis, y policitemia; ii) embolismos, sobre todo en la circulación cerebral con la producción de abscesos y accidentes isquémicos cerebrales; y iii) hemoptisis (sangrado pulmonar) por rotura de las MAV pulmonares. Entre las pruebas para el diagnóstico se emplean la radiografía de tórax, la gasometría, el ecocardiograma transtorácico con contraste y la angiografía. El tratamiento de elección es la embolización, que debe realizarse en todas las malformaciones mayores de 3 $\mathrm{mm}$. Pueden utilizarse espirales o balones inflables. Esta técnica consigue oclusiones en un porcentaje del 90 al $100 \%$ de los casos, pudiendo volver a aparecer la lesión por recanalización con el paso del tiempo. Dado el riesgo aumentado de abscesos cerebrales en estos pacientes, debe realizarse profilaxis antibiótica antes de intervenciones dentales o quirúrgicas (Shovlin, 2010; Lacombe et al., 2013).

\subsubsection{Malformaciones vasculares hepáticas}

Los pacientes con estas malformaciones suelen ser asintomáticos sin mostrar alteraciones en los marcadores de la función hepática. No obstante, pueden existir graves complicaciones clínicas cuando el paciente presenta: i) insuficiencia cardiaca de alto gasto, provocada por los cortocircuitos arteriovenosos; ii) hipertensión portal; y iii) disfunción de la vesícula biliar. La ecografía abdominal con doppler se ha usado como prueba diagnóstica, pero en los últimos años en su lugar se usa el TAC helicoidal debido a su 
mayor sensibilidad. Para su tratamiento se ha utilizado la embolización o la ligadura de la arteria hepática, pero la mejoría clínica dura poco tiempo y en algunos casos hay muerte por fallo hepático agudo. Por este motivo esta técnica ha sido desaconsejada. Por ahora el trasplante hepático es la mejor opción terapéutica para los pacientes sintomáticos, aunque no está exenta de riesgos. En un estudio preliminar se ha administrado de forma sistémica el anti-angiogénico bevacizumab (anti-VEGF) a pacientes de HHT con graves malformaciones vasculares hepáticas, siendo los resultados esperanzadores (Dupuis-Girod et al., 2012; Shovlin, 2010).

\subsubsection{Hemorragias nasales}

Los sangrados nasales (epistaxias) recurrentes de telangiectasias presentes en la mucosa nasal son la manifestación clínica más común en la HHT. Mientras que algunos pacientes presentan epistaxias ocasionales, otros tienen sangrados nasales diarios que pueden ir asociados con anemia. Muchos pacientes solo requieren suplementos orales de hierro, mientras otros necesitan transfusiones y un tratamiento nasal de emergencia. Se han descrito diversos tratamientos tópicos, sistémicos y quirúrgicos, aunque cada uno tiene una eficacia variable en cada paciente. Entre las propuestas farmacológicas, se han usado antifibrinolíticos, derivados de estrógenos, anti-angiogénicos, agentes inmunosupresores y antioxidantes. La eficacia de los agentes antifibrinolíticos, épsilon aminocaproico y ácido tranexámico se basa en la inhibición de la actividad fibrinolítica, mediante su unión al centro activo de la plasmina en los tejidos, lo que conduce a la estabilización del coágulo. El ácido tranexámico está indicado en hemorragias graves con hiperfibrinolisis, como es el caso de la HHT, y algunos estudios han descrito una disminución en la intensidad y en la frecuencia de hemorragias nasales después de la primera semana de tratamiento y una mejora en la anemia asociada de pacientes de HHT sin efectos secundarios de trombosis. Sin embargo, el ácido tranexámico está contraindicado en pacientes propensos a sufrir trombosis por los riesgos de enfermedad tromboembólica venosa. En la terapia hormonal, el uso de estradiol / noretindrona para los sangrados basales y gastrointestinales de la HHT ha mostrado un grado variable de eficacia dependiendo del paciente. El raloxifeno, otro modulador del receptor de estrógeno (SERM) similar al tamoxifeno, se ha probado con éxito en una veintena de mujeres posmenopáusicas con HHT. El raloxifeno, un SERM de segunda generación, presenta un perfil clínico mejorado frente al del tamoxifeno, y se utiliza actualmente para el tratamiento y prevención de la osteoporosis post-menopáusica. Las pacientes de HHT con osteoporosis y tratadas con raloxifeno mostraron una clara disminución en la frecuencia y en la cantidad de epistaxias. Ciertos experimentos celulares in vitro sugieren que el mecanismo de acción molecular del raloxifeno y del ácido tranexámico se debe a que aumentan los niveles de expresión de los genes ENG y $A C V R L 1$, lo que podría contrarrestar la haploinsuficiencia de estos genes en los pacientes de HHT. Los estudios del raloxifeno se llevaron a cabo en la Unidad de HHT española del Hospital de Sierrallana (Cantabria) en colaboración con el Centro de Investigaciones Biológicas de Madrid, y han servido para obtener la primera denominación de un medicamento huérfano para la HHT que la European Medicines Agency (EMA) y la Food and Drug Administration (FDA) americana han otorgado en todo el mundo.

Para el tratamiento de los sangrados en la HHT también se han usado recientemente medicamentos antiangiogénicos como el bevacizumab y la talidomida. El bevacizumab es un anticuerpo humanizado recombinante contra VEGF que interfiere en el proceso de angiogénesis y que ha mostrado resultados favorables en el tratamiento de las malformaciones hepáticas en la HHT. Sin embargo, debido a sus efectos secundarios han surgido algunas críticas respecto a su administración sistémica. Actualmente existen varios estudios en marcha usando administración tópica en las fosas nasales para reducir complicaciones. La talidomida surgió como una posible terapia antiangiogénica con varios estudios clínicos en cáncer. Tal como con el bevacizumab, una observación casual en un paciente de HHT sometido a tratamiento con talidomida para el cáncer condujo a algunos trabajos que indican un potencial uso beneficioso en la HHT. Algunos estudios mecanísticos indican que la talidomida estimula el reclutamiento de células murales, mediante el aumento de los niveles del factor PDGF-B en la célula endotelial, facilitando así el reclutamiento de las células murales llamadas pericitos (que expresan el receptor PDGFR- $\beta$ ), así como el aumento de la proliferación de pericitos. Finalmente, también se han descrito casos asilados sobre los efectos beneficiosos de: i) agentes inmunosupresores como el tacrolimus en pacientes de HHT sometidos a trasplante hepático; ii) uso tópico del timolol (un derivado del propranolol) para el tratamiento de las epistaxias; y iii) administración sistémica del antioxidante $\mathrm{N}$-acetilcisteina para los sangrados nasales (Albiñana, Bernabéu-Herrero, Zarrabeitia, Bernabéu y Botella, 2010; Dupuis-Girod et al., 2012, Lebrin et al., 2010; Shovlin, 2010). 


\subsection{Conclusiones y perspectivas futuras en la HHT}

Durante los últimos años la investigación traslacional ha permitido lograr importantes avances en la comprensión científica, diagnóstico y tratamiento de la HHT. La mayoría de los genes causantes de la HHT están bien caracterizados y codifican proteínas implicadas en la vía de señalización del TGF- $\beta$. Experimentos de manipulación genética en ratones demuestran que los dos genes mutados más frecuentemente en la HHT son esenciales para el desarrollo cardiovascular y desempeñan un papel clave en la angiogénesis. La mutación de estos genes da lugar a modelos animales que reproducen las lesiones vasculares en pacientes de HHT y también sugieren la necesidad de un estímulo desencadenante como la an- giogénesis para que se generen las lesiones vasculares. En cuanto a la terapia, no existe todavía una cura para la $\mathrm{HHT}$, pero existen una gran diversidad de medidas paliativas tanto quirúrgicas como farmacológicas que sirven para evitar complicaciones clínicas y mejoran la calidad de vida del paciente. El desafío para la próxima década es comprender mejor la base molecular de la HHT y desarrollar terapias más eficaces. Afortunadamente existen unos excelentes modelos de ratones con los que se avanza rápidamente en estos importantes campos de investigación. Además, la estrecha colaboración entre las asociaciones de pacientes, los clínicos y los investigadores básicos se muestra como un componente esencial para conseguir, a largo plazo, la cura de esta enfermedad.

\section{BIBLIOGRAFÍA}

Abdalla, S. A. y Letarte, M. (2006). Hereditary haemorrhagic telangiectasia: current views on genetics and mechanisms of disease. Journal of Medical Genetics, 43 (2), pp. 97-110. https:// doi.org/10.1136/jmg.2005.030833

Albiñana, V., Bernabeu-Herrero, M. E., Zarrabeitia, R., Bernabéu, C. y BoteIla, L. M. (2010). Estrogen therapy for hereditary haemorrhagic telangiectasia (HHT): Effects of raloxifene, on Endoglin and ALK1 expression in endothelial cells. Thrombosis and Haemostasis, 103 (3), 525-534.

Ariceta, G., Besbas, N., Johnson, S., Karpman, D., Landau, D., Licht, C. [...] y Zimmerhackl, L. B. (2009). Guideline for the investigation and initial therapy of diarrhea-negative hemolytic uremic syndrome. Pediatric Nephrology. 24 (4), pp. 687-696. https://doi. org/10.1007/s00467-008-0964-1

Atkinson, J. P., Liszewski, M. K., Richards, A., Kavanagh, D. y Moulton, E. A. (2005). Hemolytic uremic syndrome: an example of insufficient complement regulation on self-tissue. Annals of the New York Academy of Sciences, 1056 (1), pp. 144-155. https://doi. org/10.1196/annals.1352.032

Botella, L. M., Sánchez-Elsner, T., Sanz-Rodríguez, F., Kojima, S., Shimada, J., Guerrero-Esteo, M. [...] y Bernabéu, C. (2002). Transcriptional activation of endoglin and transforming growth factor-beta signaling components by cooperative interaction between Sp1 and KLF6: their potential role in the response to vascular injury. Blood, 100 (12), pp. 4001-4010. https:// doi.org/10.1182/blood.V100.12.4001
Bourdeau, A., Dumont, D. J. y Letarte, M. (1999). A murine model of hereditary hemorrhagic telangiectasia. The Journal of Clinical Investigation, 104 (10), pp. 1343-1351. https://doi. org/10.1172/JCl8088

Campistol, J. M., Arias, M., Ariceta, G., Blasco, M., Espinosa, M., Grinyó, J. M. [...] y Rodríguez de Córdoba, S. (2013). An update for atypical haemolytic uraemic síndrome: diagnosis and treatment. A consensus document. Nefrología, 33 (1), pp. 27-45.

Dragon-Durey, M.-A., Loirat, C., Cloarec, S., Macher, M. A., Blouin, J., Nivet, H. [...] y Frémeaux-Bacchi, V. (2005). Anti-Factor $\mathrm{H}$ Autoantibodies Associated with Atypical Hemolytic Uremic Syndrome. Journal of the American Society of $\mathrm{Ne}$ phrology, 16 (2), pp. 555-563. https:// doi.org/10.1681/ASN.2004050380

Dupuis-Girod, S., Ginon, I., Saurin, J. C., Marion, D., Guillot, E., Decullier, E. [...] y Faure, F. (2012). Bevacizumab in patients with hereditary hemorrhagic telangiectasia and severe hepatic vascular malformations and high cardiac output. JAMA, 307 (9), pp. 948-955. https://doi.org/10.1001/ jama.2012.250

Fakhouri, F., Hourmant, M., Campistol, J. M., Cataland, S., Espinosa, M., Gaber, O. [...] y Legendre, C. M. (2013). Eculizumab (ECU) Inhibits Thrombotic Microangiopathy (TMA) and Improves Renal Function in Adult Atypical Hemolytic Uremic Syndrome (aHUS) Patients (Pts). Journal of the American Society of Nephrology, 24, pp. 49-50A.
Faughnan, M. E., Palda, V. A., GarciaTsao, G., Geisthoff, U. W., McDonald, J., Proctor, D. D. [...] y Zarrabeitia, R. (2011). International guidelines for the diagnosis and management of hereditary haemorrhagic telangiectasia. Journal of Medical Genetics, 48 (2), pp.73-87. https://doi.org/10.1136/ jmg.2009.069013

Greenbaum L. A., Fila M., Tsimaratos M, Ardissimo, G., Al-Akash, S., Evans, J. [...] y Licht, C. (2013). Eculizumab (ECU) Inhibits Thrombotic Microangiopathy (TMA) and Improves Renal Function in Pediatric Atypical Hemolytic Uremic Syndrome (aHUS) Patients (Pts). Journal of the American Society of Nephrology, 24, 821A.

Holers, V. M. (2008). The spectrum of complement alternative pathway-mediated diseases. Immunological Reviews, 223 (1), pp. 300-316. https://doi.org/10.1111/ j.1600-065X.2008.00641.x

Jerkic, M., Rodríguez-Barbero, A., Prieto, M., Toporsian, M., Pericacho, M., Rivas-Elena, J. V. [...] y López-Novoa, J. M. (2006). Reduced angiogenic responses in adult Endoglin heterozygous mice. Cardiovascular Research, 69 (4), pp. 845854. https://doi.org/10.1016/j.cardiores.2005.11.020

Lacombe, P., Lacout, A., Marcy, P. Y., Binsse, S., Sellier, J., Bensalah, M. [...] y El-Hajjam, M. (2013). Diagnosis and treatment of pulmonary arteriovenous malformations in hereditary hemorrhagic telangiectasia: An overview. Diagnostic Interventional Ima- 
ging, 94 (9), pp. 835-848. https://doi. org/10.1016/j.diii.2013.03.014

Lastres, P., Letamendía, A., Zhang, H., Rius, C., Almendro, N., Raab, U. [...] y Bernabéu, C. (1996). Endoglin modulates cellular responses to TGFbeta 1. The Journal of Cell Biology, 133 (5), pp. 1109-1115. https://doi. org/10.1083/jcb.133.5.1109

Lebrin, F., Srun, S., Raymond, K., Martin, S., Brink, S. van den, Freitas, C. [...] y Mummery, C. (2010). Thalidomide stimulates vessel maturation and reduces epistaxis in individuals with hereditary hemorrhagic telangiectasia. Nature Medicine, 16 (4), pp. 420-428. https://doi.org/10.1038/nm.2131

Legendre, C. M., Licht, C., Muus, P., Greenbaum, L. A., Babu, S., Bedrosian, C. [...] y Loirat, C. (2013). Terminal complement inhibitor eculizumab in atypical hemolytic-uremic syndrome. The New England Journal of Medicine, 368 (23), pp. 2169-2181. https:// doi.org/10.1056/NEJMoa1208981

Lemaire, M., Frémeaux-Bacchi, V., Schaefer, F., Choi, M., Tang, W. H., Quintrec, M. Le [...] y Lifton, R. P. (2013). Recessive mutations in DGKE cause atypical hemolytic-uremic syndrome. Nature Genetics, 45 (5), pp. 531-536. https:// doi.org/10.1038/ng.2590

Llorca, O., Trujillo, A., Blanco, F. J. y Bernabéu, C. (2007). Structural model of human endoglin, a transmembrane receptor responsible for hereditary hemorrhagic telangiectasia. Journal of Molecular Biology, 365 (3), pp. 694-705. https://doi.org/10.1016/j. jmb.2006.10.015

López-Novoa, J. M. y Bernabéu, C. (2010). The physiological role of endoglin in the cardiovascular system. American Journal of Physiology-Heart and Circulatory Physiology, 299 (4), H959-H974. https://doi.org/10.1152/ ajpheart.01251.2009
Mahmoud, M., Upton, P. D. y Arthur, H. M. (2011). Angiogenesis regulation by TGF $\beta$ signalling: clues from an inherited vascular disease. Biochemical Society Transactions, 39 (6), pp. 1659-1666. https://doi.org/10.1042/ BST20110664

Noris, M. y Remuzzi, G. (2009). Atypical hemolytic-uremic syndrome. The New England Journal of Medicine, 361 (17), pp. 1676-1687. https://doi. org/10.1056/NEJMra0902814

Repetto, H. A., Rodríguez de Córdoba, S., Arrizurieta, E., Rivas, M. e Ibarra, C. (2008). Microangiopatía trombótica y Síndrome Urémico Hemolítico. En: Hernando Avendaño, L. (ed.). Nefrología Clínica (3.a ed.), pp. 286-297.

Ricklin, D., Hajishengallis, G., Yang, K. y Lambris, J. D. (2010). Complement: a key system for immune surveillance and homeostasis. Nature Immunology, 11 (9), pp. 785-797. https://doi. org/10.1038/ni.1923

Rodríguez de Córdoba, S., Esparza Gordillo, J., Goicoechea de Jorge, E., López-Trascasa, M. y Sánchez-Corral, P. (2004). The human complement factor $\mathrm{H}$ : functional roles, genetic variations and disease associations. Molecular Immunology, 41 (4), pp. 355-367. https://doi.org/10.1016/j. molimm.2004.02.005

Rodríguez de Córdoba, S., Subías-Hidalgo, M., Pinto, S. y Tortajada, A. (2014). Genetics of atypical Hemolytic Uremic Syndrome (aHUS). Seminars in Thrombosis and Hemostasis, 40, pp. 422-430. https://doi. org/10.1055/s-0034-1375296

Rodríguez de Córdoba, S., Tortajada, A., Harris, C. L. y Morgan, B. P. (2012). Complement dysregulation and disease: from genes and proteins to diagnostics and drugs. Immunobiology, 217 (11), pp. 1034-1046. https:// doi.org/10.1016/j.imbio.2012.07.021
Rossi, E., Sanz-Rodríguez, F., Eleno, N., Düwell, A., Blanco, F. J., Langa, C. [...] y Bernabéu, C. (2013). Endothelial endoglin is involved in inflammation: role in leukocyte adhesion and transmigration. Blood. 121 (2), pp. 403-415. https://doi. org/10.1182/blood-2012-06-435347

Shovlin, C. L, Guttmacher, A. E., Buscarini, E., Faughnan, M. E., Hyland, R. H., Westermann, C. J. [...] y Plauchu, H. (2000). Diagnostic criteria for hereditary hemorrhagic telangiectasia (Rendu-OslerWeber syndrome). American Journal of Medical Genetics, 91 (1), pp. 66-67. https://doi.org/10.1002/(SICI)10968628(20000306)91:1<66::AIDAJMG12>3.0.CO;2-P

Shovlin, C. L. (2010). Hereditary haemorrhagic telangiectasia: pathophysiology, diagnosis and treatment. Blood Reviews, 24 (6), pp. 203-219. https:// doi.org/10.1016/j.blre.2010.07.001

Srinivasan, S., Hanes, M. A., Dickens, T., Porteous, M. E., Oh, S. P., Hale, L. P. y Marchuk, D. A. (2003). A mouse model for hereditary hemorrhagic telangiectasia (HHT) type 2. Human Molecular Genetics, 12 (5), pp. 473-482. https:// doi.org/10.1093/hmg/ddg050

Warwicker, P., Goodship, T. H. J., Donne, R. L., Pirson, Y., Nicholls, A., Ward, R. M. [...] y Goodship, J. (1998). Genetic studies into inherited and sporadic hemolytic uremic syndrome. Kidney International, 53 (4), pp. 836-844. https://doi.org/10.1111/j.15231755.1998.00824.x

Wooderchak-Donahue, W. L., McDonald, J., O'Fallon, B., Upton, P. D., Li, W., Roman, B. L. [...] y Bayrak-Toydemir, P. (2013). BMP9 mutations cause a vascular-anomaly syndrome with phenotypic overlap with hereditary hemorrhagic telangiectasia. The American Journal of Human Genetics, 93 (3), pp. 530-537. https://doi. org/10.1016/j.ajhg.2013.07.004 